\title{
The role of partial denture in management of hypohidrotic ectodermal dysplasia
}

\author{
Tania Saskianti $^{1}$, Seno Pradopo ${ }^{1}$, Prawati Nuraini ${ }^{1}$, and Michael Josef Kridanto Kamadjaja ${ }^{2}$ \\ ${ }^{1}$ Department of Pediatric Dentistry \\ ${ }^{2}$ Department of Prosthodontics \\ Faculty of Dentistry, Airlangga University \\ Surabaya - Indonesia
}

\begin{abstract}
Ectodermal dysplasia is a rare hereditary disorder with a characteristic physiognomy. The ectodermal dysplasia constitutes a group of hereditary disorders whose clinical manifestation can be defects in ectodermal structures. The case of a 11-year-old child with hypohidrotic ectodermal dysplasia and partial anodontia is presented. Affected children require extensive dental treatment to restore appearance and help the development of a positive self image. Partial denture was provided to encourage a normal psychological development and to improve the function of the stomatognatic system. It is important for the patient and the dentist to understand that continued monitoring for dental problems is necessary. This paper had an objective to relate and discuss a case of hypohidrotic ectodermal dysplasia, with the approach of the influence of an esthetic rehabilitation and functional alternative in the improvement of the quality of life.
\end{abstract}

Key words: Ectodermal dysplasia, children, partial denture

Correspondence: Tania Saskianti, c/o: Departemen Ilmu Kedokteran Gigi Anak, Fakultas Kedokteran Gigi Universitas Airlangga. Jln. Mayjend. Prof. Dr. Moestopo no. 47 Surabaya 60132, Indonesia. Email: taniapedo@yahoo.com

\section{INTRODUCTION}

Ectodermal dysplasia is part of a group of hereditary diseases that may affects the development of two or more ectodermal derived structures, for instance, hair, fingernails, teeth and skin. It is more frequent in boys and mostly case is recessive autosomal character, but it could be dominant autosomal or linked to chromosome X. The pathognomy of the face in ectodermal dysplasia individuals of both sexes is similar and could be characterized. ${ }^{1,2}$ The types of dysplasia commonly observed are the hypohidrotic and anhidrotic. The first has as principal characteristics such as scarce hair, dystrophic fingernails and dental anomalies, involvement of the sudoriparous and sebaceous glands are not presented. The most common type of their anomaly is hydrotic ectodermal dysplasia. The major clinical findings of the disease are sparse hair, dryness of the skin, irregularities in nails, hypodontia or anodontia, hpohydrosis and hypotrychosis.

Anodontia or hypodontia, abnormal crown form shown with clinical shape, and short root with large pulpal chamber both in deciduous and permanent teeth are some of oral findings presented in ectodermal dysplasia. ${ }^{3-5}$ Multiple dental absences as well as reduced vertical face dimension and, as consequence, resulting in protuberant lips besides the facial aspect of senility because of the decrease of the vertical dimension. Saddle-shape nose, malformed and protruding ears, wrinkles around eyes, pigmentation disturbances, disorders in sexual and mental development are the other features of this disease. Additionally, disphonia and hoarseness of the voice may be determined due to the atropic pharyngeal and laryngeal mucosa. ${ }^{6}$

Ectodermal dysplasia may also cause a physical and emotional problem. Ectodermal dysplasia patients require dental treatment primarily because of other dental needs and not always for good appearance. Restoration of good appearance is merely one of the outcomes of a successful treatment. ${ }^{7}$ Oral rehabilitation is one of the possible means to improve the quality of life. In this way, the objective of the present article was to describe a case of an hypohydrotic type of ectodermal dysplasia, with the approach of the influence of an esthetic rehabilitation and functional alternative in the improvement of the quality of life.

\section{CASE}

In 1999, a three year-old male patient, was referred to the Airlangga University, Faculty of Dentistry, Surabaya, Indonesia for examination and treatment of his disorder. On clinical examination, he exhibited some dental absences and presented with "small" teeth (Figure 1).

History of pregnancy and delivery were normal. No systemic disorders or medication were documented. Family history revealed that the parents were healthy, however his brother and grandfather showed the similar disorder. The extra oral examination (Figure 2) revealed the typical facial physiognomy of hypohidrotic ectodermal dysplasia with prominent forehead and ears, protuberant lips and a saddle nose. A diminished lower facial height 


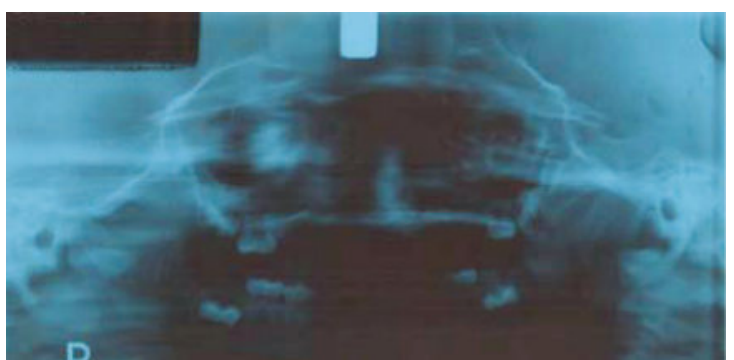

Figure 1. Panoramic X-ray on August 1999 showing the dental agenesis.

contributed to a senile facial expression. The intraoral examination revealed partial absence of primary teeth (Figure 2).

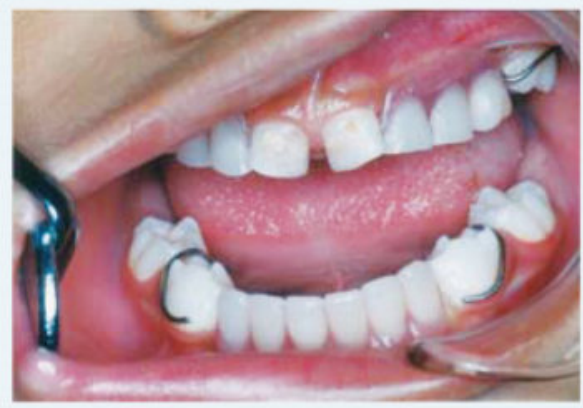

Figure 2. Removable partial denture.

The tongue was relatively large, but no signs of macroglossia could be detected. After the permission was received from the parents for the presentation of the

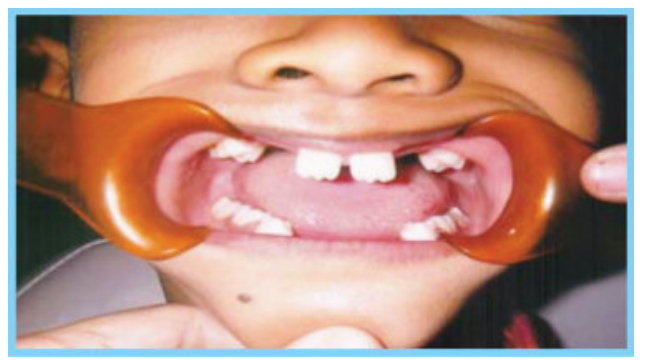

Figure 3. A clinical view of the upper and lower arch, notice the dental absences and conoid teeth.
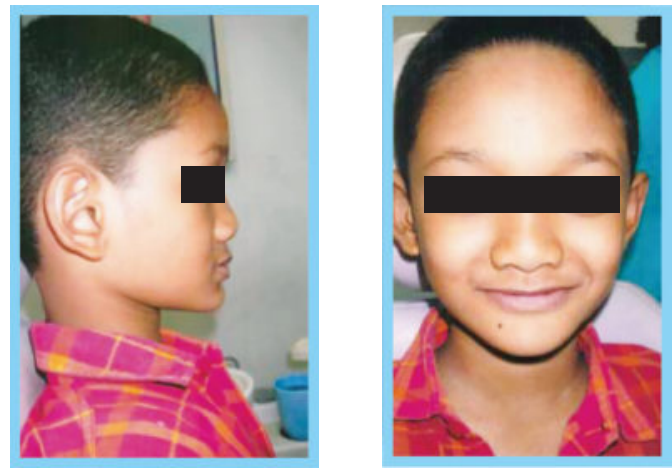

Figure 4. Patient, 10 years old with hypohidrotic ectodermal dysplasia. child, full history with clinical examination and radiologic findings were obtained. Radiographic examination (Figure 3 and 4 ) revealed the partial absence of permanent tooth germs.

\section{CASE MANAGEMENT}

The initial treatment plan in 1999 was to prepare maxillary and mandibular acrylic removable partial denture, for the patient. Considering that the patient are too young to receive extensive prosthodontic treatment. The partial denture was use to restore the function and aesthetics (Figure 5). The teeth were preserved without the need for restoration and extractions. In the present case the amount of saliva was sufficient for the adhesion of the dentures. These prosthesis need to be changed periodically according to the bone growth and development. The patient was monitored to perform a proper and efficient hygiene of the prosthetic appliances. He was satisfied with his aesthetic.

In 2005, the patient began to feel discomfort due to changes in hard tissue structures so that he subsequently rarely used his dentures. On clinical examination, the permanent central incisive and first molar has erupted (Figure 3 ). The extra oral examination showed the characteristic of hypohidrotic type of ectodermal dysplasia as described above (Figure 4). The panoramic radiographic showing the dental agenesis (Figure 5). He had another removable partial denture (Figure 6).

At recall appointments, he complained of fatigue on his temporomandibular joint because of posterior open bite. Occlusal grinding was taken on the incisal edges of mandibular incisive also to improve his mastication.

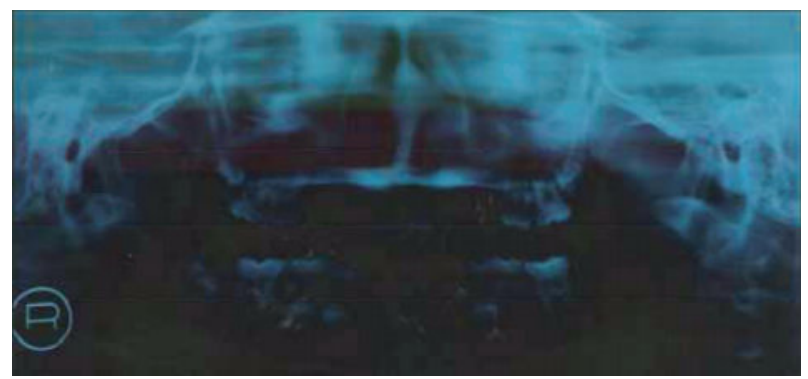

Figure 5. Panoramic radiographic on December 2005 showing the dental agenesis.

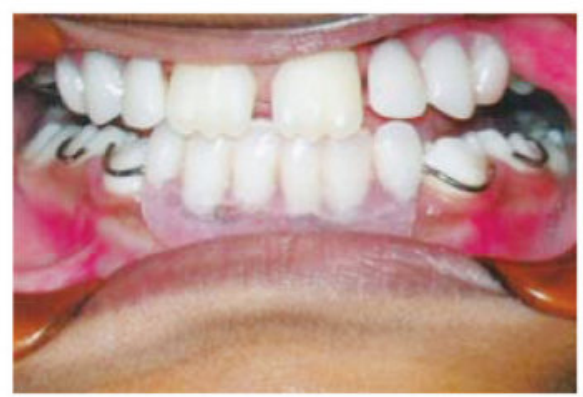

Figure 6. Removable partial denture, a frontal view of the patient occlusion. 

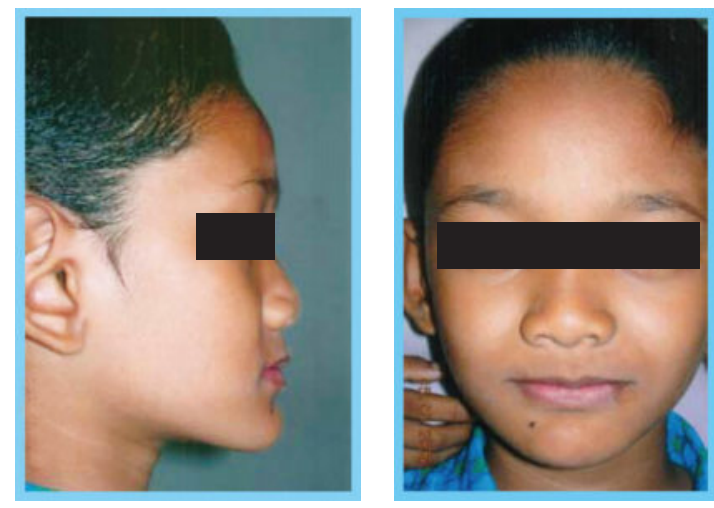

Figure 7. A facial view after treatment.

\section{DISCUSSION}

Although most infants begin tooth eruption by 6 months of age, there is tremendous variation. In general, if the infant is growing, gaining, and has normal other ectodermal structures like hair, skin, and nails, and there are no dysmorphic features, no evaluation is necessary other than reassurance. Normal number of primary teeth is 20 and there are 32 permanent teeth. Mandibular central incisors are often the first to erupt followed by the maxillary central and lateral incisors. There may be familial cases of absence of individual teeth and certain conditions may be involved with delayed or absent tooth development. Some are: down syndrome, ectodermal dysplasia, hypothyroid or hypopituitary. ${ }^{8}$

Ectodermal dysplasia is commonly diagnosed in childhood, subsequent to a feverish episode of unknown origin. ${ }^{9}$ In many cases the diagnosis has been made by a pediatric dentist because missing teeth or the delay in teething often starts to worry the parents and leads them to visit the pediatric dentist. ${ }^{10}$ A pediatric dentist should not hesitate to radiographically examine a patient whose teeth have not erupted by the appropriate age in order to exclude ectodermal dysplasia. The screening limit for the first tooth to erupt is 15 months. ${ }^{10}$ If that stage aplasia of several teeth is seen, the patient should be referred to a geneticist in a pediatric unit with a suspecsion of ectodermal dysplasia (ED) diagnosis. The diagnosis of ectodermal dysplasia is extremely easy when the patients presents with more characteristics and clear clinical forms. In this case report when these characteristics are less evident, the diagnosis and the classification of the patient, became a difficult task for the pediatric dentist.

In ectodermal dysplasia it was possible to improve the physical condition of the child, as well as the esthetics; the chewing and phonetic functions (Figure 7). The dental treatment was done not only to re-establish the function, but to improve the emotional and social aspect of the child as well.

In patients with ectodermal dysplasia, tooth agenesis and its secondary effects on growth and development of the jaws is often the most significant clinical problem. It is necessary to use the prosthetic appliances to the reestablishment of aesthetics and function, normalize the vertical dimension and support the facial soft tissues also to improve speech. The most common treatment in cases of ectodermal dysplasia with partial anodontia is partial dentures as used in the present case as an early treatment strategy. This favorable treatment has been suggested by several author. ${ }^{11-18}$

The denture must be periodically modified as alveolar growth, erupting teeth and rotational jaw growth change both the alveolar, occlusal and basal dimensions. ${ }^{19}$ After the repair of the prosthesis, the patient able to enjoy a better quality diet because he could then chew better he presented a positive feedback regarding psycho-social living, thus improving the quality of life. The patient could develop the social relationship with his peers because his aesthetic appearance was improved, and the problem of hoarseness disappeared which helped him to improve psychologically. This alternative treatment was successful as it established his masticatory speech functions and improved his social living, hence quality of the life of the patient. Future treatment will include modification or replacement of the dentures according to the observed skeletal growth. Some authors ${ }^{20}$ recommend the placement of implants in the adult phase for the treatment of patient with ectodermal dysplasia, although another author ${ }^{21}$ suggest the placement of implant in a 3 year-old child.

Another treatment for some reasons in young children, we prefer to apply crown and bridges if they have also a limited retention and stability, a fastened bone destruction of an already hypoplastic alveolar process and the middle of the upper jaw is covered and so it blocks the sutural growth. ${ }^{19}$ The use of certain kinds of dentures depending on the patient's age, eliminates esthetics, psychological, functional and speech disorder issues. ${ }^{22}$ As long as there are no physical, psychological or social burdens, no further treatment is necessary. ${ }^{19}$

\section{REFERENCES}

1. Kupietzky A, Houpt M. Hypohidrotic ectodermal dysplasia: Characteristics and treatment. Quintessence Int 1995; 26:285-91.

2. Sabah E, Çalıskan MK, Aydyn Z. Üç olgu nedeniyle ektodermal displazinin endodontik ve protetik tedavisi. EDFD 1988; $9(3): 45-54$.

3. Vierucci S, Baccetti T, Tollaro I. Dental and craniofacial findings in hypohydrotic ectodermal dysplasia during the primary dentition phase. J Clin Pediatr Dent 1994; 18:291-7.

4. Chitty LS, Dennis N, Baraitser M. Hidrotic ectodermal dysplasia of hair, teeth, and nails: case reports and review. J Med Genet 1996; 33:707-10.

5. Bonilla ED, Guerra L, Luna O. Over denture prosthesis for oral rehabilitation of hypohidrotic ectodermal dysplasia: A case report. Quintessence Int 1995; 28:657-65.

6. Itthagarun A, King NM. Ectodermal dysplasia: A review and case report. Quintessence Int 1997; 28:595-602.

7. Ali Rıza ALPÖZ. Hydrotic ectodermal dysplasia (Associated with numerous enclosed permanent teeth including a primary molar). Tr J of Medical Sciences 1999; 29:75-9. (C) TÜBITAK 
8. Creighton PR. Common pediatric dental problems. Pediatric Clinics of North America. 1998; 45(6):1579-600.

9. Daniella DV, Ana Beatriz AC, Lucianne CM, Joao AF. Alternative rehabilitation treatment for a patient with ectodermal dysplasia J Clin Pediatr Dent 2004; 28(2): 103-6.

10. Pirinen S. Therapia odontologica. In: Meurman, Murtomaa, LeBell, Autti, Luukkanen, eds. Helsinki: Academica Kustannus Oy; 1996. p. 414.

11. Borg P, Midtgaard K. Ectodermal dysplasia: report of four cases. J Dent Child 1977; 44:314.

12. Shore SW. Ectodermal dysplasia: a case report. J Dent Child 1970; 37:254-7.

13. Boj JR, Von Arx JD, Cortada M, et al. Dentures for a 3-yr-old child with ectodermal dysplasia: case report. Am J Dent 1993; 6:165-7.

14. Cook, WA, Kane FJ, A Family history of hereditary anhidrotic mesodermal-ectodermal dysplasia. J A D A 1968; 76:1032-37.

15. Bergendal T, Eckerdal O, Hallonsten AL, et al. Osseointegrated implants in the oral habilitation of a boy with ectodermal dysplasia: a case report. Internat Dent J 1991; 41:149-56.
16. Boj JR, Duran J, Cortada M, et al. Cephalometric changes in a patient with ectodermal dysplasia alter placement of dentures. J Clin Pediatr Dent 1993; 17:217-20.

17. Till MJ, Marques AP. Ectodermal dysplasia: treatment considerations and case reports. Northwest Dent 1992; 71:25-8.

18. Belanger GK. Early treatment considerations for oligodontia in ectodermal dysplasia: A case report. Quintessence Int 1994; 25:705-11.

19. Mortier K, Wackens G. Ectodermal dysplasia anhidrotic. Orphanet Encyclopedia 2004 September. Available at: http://www.orpha. net/data/patho/GB/uk-ectodermal-dysplasia-anhidrotic.pdf

20. Ekstrand K, Thompson N. Ectodermal dysplasia with partial anodontia: prosthetic treatment with implant fixed prosthesis. J Dent Child 1988; 55:282-4.

21. Guckes AD, McCarthy GR, Brahim J. Use of endosseous implants in a 3-year-old child with ectodermal dysplasia: case report and 5-year follow-up. Pediatr Dent 1997; 19:282-5.

22. Pervin I, Sina U, Seda GH. Surgical and prosthodontic treatment alternatives for children and adolescents with ectodermal dysplasia: A clinical report. J Prosthet Dent 2002; 88:569-72. 